Schools Collaborating with Experts in the Community

\title{
Sharing our gifts with the community
}

\section{EPUNI PRIMARY SCHOOL AND THE COMMON UNITY PROJECT AOTEAROA}

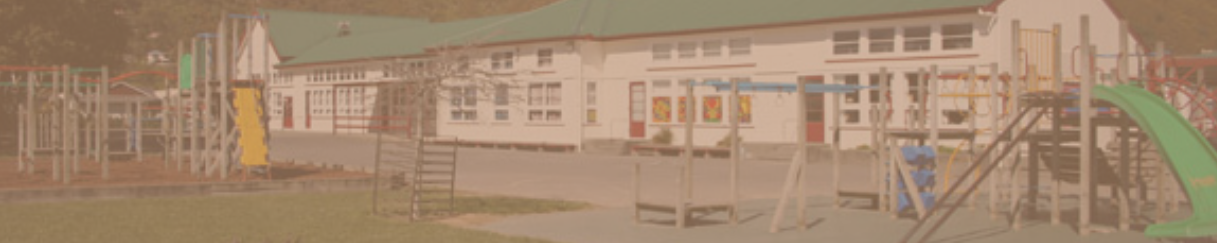

\section{GGGNZCER

New Zealand Council for Educational Research P O Box 3237

Wellington

New Zealand

www.nzcer.org.nz

ISBN 978-0-947509-38-5

(c) NZCER, 2016 


\section{Acknowledgements}

NZCER would like to thank the leaders, staff and students at Epuni Primary School and the staff and volunteers involved with Common Unity Project Aotearoa. We are especially grateful to those who took part in the interviews and shared their insights as we were undertaking this study. 


\section{Contents}

Acknowledgements iii

1. Introduction 1

2. Research design 3

3. Epuni Primary School 4

4. Common Unity Project Aotearoa 6 How did CUPA get started? 7

5. Connection, relationships and trust: Navigating the terrain 8

6. How does community involvement connect with the school curriculum? 10

7. How does community connection benefit the students? 12 Benefits for teachers 13 Benefits for community 13

8. Sharing the learning with other schools and communities 15

9. Conclusion 16

References 17 


\section{1. Introduction}

We will empower our learners to recognise and strengthen their gifts and give them opportunities to share these with others in the wider community. (Epuni Primary School mission statement)

This report presents findings from a case study carried out by the New Zealand Council for Educational Research (NZCER), focusing on Epuni Primary School and its collaboration with community members, including a partnership with the Common Unity Project Aotearoa (CUPA), a grassroots community-based initiative. It is the third case study carried out as part of a wider investigation into successful and sustained collaborations between New Zealand schools and community and professional experts ${ }^{1}$ that support relevant, connected, future-oriented learning ${ }^{2}$ for students. The first case study, All the school's a stage (McDowall \& Whatman, 2016a), described a collaboration between performing and visual artists and staff at Pakuranga Intermediate School. The second case study, Creating a belonging place (McDowall \& Whatman, 2016b), discussed the role of community experts at Owairaka District School.

The research project is informed by six principles for future-oriented learning hypothesised by Bolstad and Gilbert, with McDowall, Bull, Boyd, \& Hipkins (2012), in particular, principle six which argues that new kinds of partnerships and relationships between schools and the wider community will be necessary to support a more future-oriented education system. The rationale for this argument is that schools, on their own, can't provide access to all of the knowledge and expertise that today's learners need in order to be fully engaged citizens now and in their futures. Students need opportunities to access knowledge and expertise held within the wider community, and opportunities to develop their capabilities in authentic contexts; for example, using knowledge in ways that contribute to the community, as well as to their own learning and development. We have argued that schools can and should play a key role in orchestrating these kinds of learning opportunities.

1 By "community and professional experts" we mean people who are not necessarily educators or teachers, but who have knowledge and expertise in their own professional areas (or because of their role in the community) and are working with schools in ways that support learners to connect with that knowledge and expertise.

2 By "future-oriented learning" we mean approaches and practices that align with contemporary perspectives about the kinds of learning and learning opportunities young people need in order to have a good life in a well-functioning society for the 21st century. (This kind of learning overlaps with, but also goes beyond, current frames of learning success such as achievement and progression into tertiary education and employment.) 
The core argument for the type of school-community relationships we are focusing on is their benefit for students' learning. However, one focus for this research was to understand experiences of adults who work together in these collaborations; that is, the teaching professionals and the community experts. What are the impacts for them? The reason for this focus is that adults (as teachers, school leaders, policy decision-makers, parents or voters) shape the educational system. For system-wide shifts to occur, it is important to know how and why adults think it is beneficial for school learners to have access to community expertise as part of their school learning, and how they think this can happen effectively. 


\section{2. \\ Research design}

We chose a case study approach as being most appropriate to address the "what", "how" and "why" of a situation (Yin, 2003). The advantage of a case study approach is that it can provide the "force of example" (Flyvbjerg, 2006, p. 228) as a source of understandings. As noted by Flyvbjerg, the advantage of the case study is that "it can 'close in' on real-life situations and test views directly in relation to phenomena as they unfold in practice" (Flyvbjerg, 2006 p. 235).

We selected Epuni Primary School as a case study because, like Pakuranga Intermediate School and Owairaka School, it was an example of a sustained relationship between a school and people in the community with expertise that was different from that of the teachers and school leaders. We visited the school six times between March and June 2016 to interview the school principal, a teacher with a special responsibility for community relationships, the leader of the Common Unity Project Aotearoa (CUPA) and a group of students in Years 2, 4, 5 and 6. We did not interview additional whānau and community members, mainly due to time constraints. We acknowledge this as one limitation of the case study. However, those we did interview all commented on the range of perspectives they picked up from whānau and the school's community, and the diversity of these views is reflected in our case study account. Following the case study visits we identified key themes from our visits and interview notes and used these to structure the findings presented in this report. 


\section{3. Epuni Primary School}

Epuni Primary School is a small, long-established Hutt Valley primary school with large grounds. The principal has been at the school for many years and knows the community very well. The by-line on the school's website is: "Success for every learner. Every learner is a treasure" and the website identifies the school's commitment to all learners:

Your child's success is our goal. We provide a warm supportive environment with endless opportunities for all learners to learn and take pride in themselves and the school. We cater for academic, social, physical and cultural needs and in doing so challenge each child to succeed. (Epuni Primary School website)

Excerpts from a 2014 ERO report acknowledge the realisation of this goal and of the mission:

Epuni Primary School is a positive and welcoming place for students, their families and the community. Learning is meaningful and enjoyable for students. Teachers use strategies that make learning a positive and enjoyable experience. (Epuni Primary School website)

Student wellbeing is fostered. Culture is acknowledged and valued. Relationships between teachers, students, their peers and participating adults are positive. (Epuni Primary School website)

The community is always welcome in the school, and the school uses its website and Facebook account to communicate with whānau ${ }^{3}$ and the community, sharing news and posting about events in and around the school. Junior classes are beginning to use an app called Seesaw to share children's learning stories with whānau. In 2016, one teacher, Ancey, was given a special role in engaging with whānau to identify things they would like to make happen in the school, and working with whānau to make these ideas happen. Ancey's work with whānau will be discussed later in the case study.

The school website includes a page explaining its partnership with CUPA, described as a project about:

... growing food, skills and leadership with local families ... we hope to provide a place of learning, an environmental hub for learning sustainability practices, food production and adult education. It is our deepest wish that the parents and children of Epuni School are strengthened in skills and knowledge throughout the project duration.

(www.epuni.school.nz/partnership-with-common-unity.html)

3 Whānau is inclusive of all parents and caregivers. 
Knowing the origins and development of the relationship between Epuni Primary School and CUPA is an important part of understanding how the two organisations work together and independently to foster local community connection and engagement. Both organisations are working to strengthen community bonds, build capabilities within the local community and draw on diverse forms of community expertise to the benefit of school students as well as the community. CUPA is co-located on the grounds of Epuni Primary School, and collaborates with students and teachers on various community projects and activities, many of them centred around sustainable food production. Students and teachers are regularly involved in activities around the school grounds such as working in the garden, planting, harvesting, seed collection, food preparation, cooking and other activities.

In addition to their shared endeavours, each organisation also engages with the community in its own ways, in line with their goals, philosophies and purposes for community engagement, and each is governed by their own board. At the centre of the relationship between Epuni Primary School and CUPA is a relationship between its respective leaders-Bunnie, the principal of the school and Julia, the project coordinator of CUPA-who used to be next-door neighbours. In this case study we weave together the stories of both organisations as told through the interviews. 


\section{4. \\ Common Unity Project Aotearoa}

Bringing our students, parents and wider community together to learn new skills and foster true social sustainability is a core focus of our project. (http://www.commonunityproject.org.nz/unity-garden/)

The Common Unity Project Aotearoa is a registered charitable trust funded by philanthropic grants, service contracts, donations and fundraising. The project provides a range of activities designed to "educate, unite and empower" the community. Activities are based at Epuni Primary School and currently include the garden, a koha kitchen, a playgroup, sewing and knitting sessions and a sunflower production project (Project Sunshine) where seeds are packaged by students and sold or donated to schools and people all over New Zealand. ReCycled Rides is a community bike library offering rescued, fixed-up bikes to Epuni and the wider Hutt Valley community, and the project has included building a bike track around the school grounds which is used by students and the community.

CUPA has a weekly timetable of activities staffed by community volunteers:

- Monday mornings: feeding a family of four for $\$ 100$

- Tuesday mornings: gardening with students from the school

- Wednesday mornings: Koha Kitchen and community playgroup

- Thursday mornings: small piece knitting group (volunteers teach students to knit)

- Friday mornings: sewing cooperative

- Saturdays: community gardening and recycled rides.

Students from the whole school are involved in all stages of food production in the garden: composting, preparing beds, sowing seeds, planting seedlings, weeding, watering, harvesting and saving seeds. On Wednesdays, community volunteers and students work together to prepare lunch meals for three days a week using garden produce as part of the Koha Kitchen initiative in the school hall kitchen. 


\section{How did CUPA get started?}

CUPA emerged several years ago out of "an ongoing conversation" about needs in the community, culminating in Julia presenting a proposal to the school board of trustees requesting permission to convert part of the old soccer field into a community garden that would grow food for the children and community. This took some negotiation, as there were some concerns from the board that needed to be worked through. For example, the board had concerns about factors such as the location, prevailing winds, how the garden might affect neighbours and what guarantees there were that the garden would be maintained over time:

We learned not to underestimate the amount of cooperation and negotiation needed to establish the partnership. (Principal)

Ultimately, the board gave permission, and the garden project got underway. The gardens were established with help from networks in the community, with enough funding for equipment and materials for a couple of years gathered through a successful crowd-funding campaign:

The original intention was to see if we could grow enough food to be feeding the children and to engage the community in that process using a community led approach rather than a service provider model. (Julia, CUPA project coordinator)

In the early days before the gardens were producing, fresh produce was also purchased as the lunch cooking programme began almost immediately.

Since the beginning of the initiative 3 years ago, CUPA has evolved to include several different microprojects that have emerged through CUPA's engagement with the local community. Current projects that have emerged out of the CUPA programme include a sewing cooperative and a honey production project:

Sewing group started as a session offered to the community to repair their clothes and do some basic sewing and that has grown in to a business now. So it wasn't the intention to ever end up with a sewing business but that is what we have got now and it's fine, that's where [the community members] have taken it. (Julia, CUPA project coordinator)

The way in which CUPA operates reflects an underpinning philosophy of supporting the community to develop capacity to generate and sustain its own projects, initiatives and employment opportunities-not providing a "service model" to the community:

Every day I wake up and as I am driving to work I am reminding myself that the intention of my day is to make myself unemployed and that is a completely different shift to 'every day I come here to do something to this community'. Because 'doing something to' means I am a service provider, but using the idea of 'I make myself unemployed' means that I am enabling someone else to do what I might be doing. We are really big on creating as much employment around here as we possibly can. (Julia, CUPA project coordinator) 


\section{5. \\ Connection, relationships and trust: Navigating the terrain}

What happens when a grassroots community project starts to evolve on the grounds of a communityoriented primary school? One of the interesting challenges for Epuni Primary School and CUPA has been to accommodate different ideas and expectations around what the school can do for the community and vice versa, who decides what "the community" wants or needs and how the school and community work together to achieve shared aims.

As the principal describes it, community involvement has long been part of Epuni Primary School life:

We have always been totally community-based and have a huge amount of support from the community ... A lot of the success of community involvement is to do with the small size of the school. Parents are hands-on, and respect our values. (Principal)

The principal favours the term connection rather than engagement, "as the relationships have got to be equal. Connection is trust." This connection with the community is maintained in many ways through weekly school life:

We have occasions in school on Monday mornings. These are family times where there is singing and we focus on key competencies and values. We give out certificates, welcome new students and applaud school sports representatives. About 15 parents and whānau come each Monday. Every second Friday at the end of the day we have a celebration of learning which attracts higher numbers of whānau. Whānau help out with clubs, sports coaching and other support. (Principal)

The emergence and evolution of CUPA within the school has raised issues that have had to be worked through carefully in order to maintain a trusting relationship between CUPA and the school. For example, some were concerned that the growing public profile of CUPA might overshadow the school itself:

Our parents are passionate about what happens at the school; they were worried about the soul of the school. They said: 'We are not a vehicle to promote you [CUPA].' (Principal) 
Questions around profile and visibility of CUPA and Epuni Primary School, and how each benefited from their stories being shared more widely, have been worked through via ongoing conversations between Julia and Bunnie and their respective boards, and it was clear from our case study interviews that there are still differing opinions within and across the school and community about the school's relationship with CUPA, the use of school grounds and school resources for various activities, the extent to which the school, students and whānau benefit from CUPA's presence in the school. Other things that were mentioned included:

- different opinions about some of the current CUPA activities happening in the school

- why CUPA activities might not engage or appeal to all school whānau

- differing values and perspectives to do with "giving and receiving" and whether the balance between these is right when it comes to students receiving things at school or from the community

- challenges related to planning and communication between the school, CUPA, their respective communities and the wider community

- different opinions about which aspects of the relationship between Epuni Primary School and CUPA should grow, reduce or continue into the future.

Although all students are fully engaged with the garden project and work in the gardens regularly, the original idea that developing the gardens on the school site would encourage and teach the community how to establish their own food gardens wasn't popular with everyone:

... feedback that I have had about that is well actually it looks really hard work [gardening] and we don't want hard work, we are done with hard-everything is hard in our lives and now you want me to dig up my backyard and grow vegetables and, no, but sewing absolutely. Anything creative [or] cooking, they love coming for the cooking, lots of mums over there [in the kitchens] this morning 'but just don't give us hard', and I get that. (Julia, CUPA project coordinator)

Some members of the school and community have been wary of the gardening project having too high of a profile in the public eye, compared with all the other ways the school is engaging with and responding to the aspirations of its students, whānau and community.

Both Epuni Primary School and CUPA seem to be attentive to community feedback and have each responded in proactive ways. For example, in 2016 the principal gave a teacher a special responsibility for liaison with parents and whānau. This liaison work is separate from CUPA and includes all community members. The aim was to encourage parents and whānau to generate ideas about things they would like to do with and for their school. The teacher in charge of this community liaison was aiming for an open and inclusive forum for all families and whānau:

I wanted to get all families participating in the school-not just the ones who already were. (Ancey, teacher in charge of whānau engagement)

The whānau group started to meet regularly and decided they would create a fundraising event for the whole school community, to raise money for hip hop dance lessons for the students with a local dance crew. This event happened in Term 2 and was very successful with high levels of parent involvement.

As discussed, for CUPA the initial community gardens approach has evolved and morphed into many different projects and opportunities for the community to come into the school to learn, share and work on different kinds of projects. CUPA and the school keep their communication channels open, while each also works on its own projects and endeavours. Some areas of tension and differing views on what is or is not working well remain, and were raised throughout the case study interviews. The touchpoint across both organisations seems to be that children and their needs must be the central focus for what they do:

In each and every interaction that we have with the community it is about the meeting of our children's needs so that is our place of unification. (Julia, CUPA project coordinator)

At the centre is the students-they are the most important thing. (Principal) 


\section{6. \\ How does community involvement connect with the school curriculum?}

The school develops a long-term curriculum plan for the year and identifies which learning areas will be a focus. Literacy and numeracy are always included. The school curriculum is planned around a big theme for the year, with a focus for each term to guide student inquiries:

This year it is 'My place to stand'-term one it was 'My place to stand within my class and my homeconfident and safe and secure within a group'. This term it is 'My place to stand within the school and beyond the school'. (Ancey, teacher in charge of whānau engagement)

Community members and whānau might be engaged in a variety of ways to support student learning, depending on the directions students and their teachers go with their inquiry projects:

[In inquiry planning students are encouraged to think] who are your experts out there? How can you contact those people? Seniors (Years 4, 5, 6) will make phone calls to community and plan who will do what in their groups and carry that through. The teachers' role is to support the students, prompting them with questions and getting them to think for themselves. A lot of them will think of family members. (Ancey, teacher in charge of whānau engagement)

In terms of linking with CUPA activities, the school's curriculum plans are shared with Julia and with other community and whānau in the school so that they can support curriculum goals into their work with students; for example, when working in the garden:

It is very easy to teach anything out of a garden really ... here is an example, maths ... I was working with the seniors yesterday, they are working on sequencing. We had a planting day where we used the plants and soil as a way of marking out sequences in groups. That took in to consideration [of] the figuring out how much space each plant needed, the width of garden beds, the other companion plants that we needed to put around, the whole thing so we mapped it out as a sequence and did it. (Julia, CUPA project coordinator) 
As well as using the garden to support the school's curriculum intentions, Julia's work with learners in the gardens also gives life to its own broad and holistic curriculum:

... one of our objectives is by the time our senior students have left the school that there are key things that they know how to do. And they are things like knowing how to save a seed. They have an understanding of water conservation, that they know the cycle of their food, that food does not start and end in the fridge, in the rubbish bin, that food starts in the garden, comes in to the kitchen, returns to the compost and that they can see that living, breathing cycle of food production and that it is a circular activity not a linear one. And that they also have some values attached to that which I share, they share, we are really big on sharing and making sure that the needs of people around us are met through the action of our own hands. (Julia, CUPA project coordinator)

Julia aims to connect children to deep concepts in the permaculture garden and food forest; for example, about interdependence and community:

One of the best little projects that we put in to the garden is actually our food forest; what the children learn from that food forest experience is actually plants live in communities, so we are again using that metaphor of community. And I do not stand or walk alone, that I need all of this diversity around me and that just as I live in a community, the community that I live in is an ecology too ... (Julia, CUPA project coordinator)

Some work is currently underway to further develop this curriculum in a way that it can be shared with any teachers and schools interested in the use of permaculture principles and gardens as places for learning linked to the curriculum.

Some of the core values and principles central to CUPA's approach have resonated across the school culture; for example, the concept of reciprocity or "the giving hand and the receiving hand" which was mentioned by the principal and students we interviewed:

Julia's concept of giving and receiving hands has worked well. We are looking at ways children can go out into the community and help. The students have had so much coming in. We will organise students to weed the new Naenae community garden; to cook lunch for the whole school. Service is empowering for students; it is showing students they are valued. (Principal)

The school is open to other ideas that Julia suggests for the children, like forming a "bug club" to learn about insects. Children frequently carry learning experiences from the garden and other activities back into the classroom and use these in their writing:

In my class sometimes we do free writing and sometimes it's writing a topic to explain things, and if you don't have something to write about it's five main points. Some people choose the garden because they know much information about it. (Year 6 student)

Some of the students we interviewed also told us how the layout of the community garden was based on a mandala:

At the centre is meant to be a special apple tree I think from up north. Then with everybody talking about mandalas, then everyone made a mandala with themselves in the middle. With what they love on one side, and what they respect, and what they're grateful for. $\mathbf{Q}$. Why is the garden like a mandala? We never really got told, I think there is probably a reason but what I heard was that it was respect for the planet, a mandala. (Year 6 student)

The idea of a mandala has become important to Epuni Primary School, and through extensive discussion and consultation the school developed its own mandala to represent the school's vision and values.

Thus, by all accounts, the school curriculum and the CUPA curriculum directly and indirectly interact and influence each other through shared values and the integration of the children's learning experiences. 


\section{, \\ How does community connection benefit the students?}

Everyone we spoke to talked about the benefits for students of having the community present and involved in their learning experiences at Epuni Primary School, through CUPA activities and other community and parent involvement:

You see the children light up-'my mum's here or my dad's here'-you see the student's focus and getting her work done. Whenever I can, I will grab a parent to read to a student; or if a parent is here I encourage them to go into different classes where their children are. Children love it. A group of parents and whānau would stay on or come early at the end of the day-sing with us, do karakia, joining in. (Ancey, teacher responsible for whānau engagement)

The children all know [the community members] by name, they are all extra special people that come in ... we call them our friends from our wider community. (Julia, CUPA project coordinator)

The students we interviewed mentioned many different community people who helped them in all sorts of different ways, from helping their reading, to sports coaching and physical education, cooking and knitting and learning about technology:

Cool just to get the community involved with kids, parents involved with children, I reckon it's just fun. (Year 6 student)

Without the community we wouldn't be that smart and we wouldn't have a huge garden to make our lunch, because there are some people here who don't always get lunch. (Year 4 student)

We asked students about some of their proudest achievements in things they'd done with and for the community. Each student thought of something different, including some recent experiences and some from years prior. For example: 
Cooking! Cooking is amazing, especially with the parents. (Year 4 student)

[Name of community member] helps me with my cross country. Every second or first lunch we have to do training, we have to do 8 laps and that's how I got into interzone, he just kept on encouraging me saying 'you can do it you just have to go a bit faster each time'. I'm getting faster and faster. He keeps on encouraging me. (Year 4 student)

One of my proudest things was setting up when the Mayor was coming. We had this gigantic screen, we skyped a Japanese school. It was where the Japan Mayor was. We had a TV that we wheeled around with the extension cord and we did kapa haka and I did a presentation. It was a technology thing, because me and a few other students who came, we knew how to set it up. We knew how to run the system. Q. How did you know how to do that? Originally we got taught by [classmate's] dad. He taught us about circuits, lights, projectors, and yeah. Q. So he taught you and now you can help the school? Yeah. (Year 6 student)

The students referred to "the giving hand and the receiving hand", and discussed some of the ways they were contributing to their communities as well as receiving from the community:

I think it happened last year, we went to the hospital and the children's ward. We went to see the sick ones because they didn't usually get to have Christmas with their family. We gave them heart shaped things with special stuff in it and they loved it. After the first year of knitting, I think we donated some of the blankets. (Students)

The students' inquiry projects this term were focused around the technology learning area, and students also gave examples of how their projects would be with others in the school and community:

We're looking at making a game, and showing it to other classes or maybe take it out in the community. We tested our games with Room 5, now we're going to take them to our house and maybe outside, and go and show people how to play them. (Year 4 student)

\section{Benefits for teachers}

Ancey, the teacher with the responsibility for whānau engagement, enjoys being networked with the community as a teacher, and as parent herself:

I get lots of good things from community engagement: friendship, students beaming when whānau are involved, new learning, whānau getting support by being involved. My core business is the wellbeing of children and I also get good tips on parenting.

We did not interview other teachers, but the teacher responsible for whānau engagement thought that all staff interact and build rapport with parents around the children's learning and involving the community in school life:

The door is always open [to the community]. (Ancey)

Some teachers have been more hands-on and engaged with the CUPA project's activities than others, and students' weekly time in the garden has been negotiated so that teachers don't feel that students miss out on important classroom learning time.

\section{Benefits for community}

Between CUPA activities and the whānau engagement work, the range and number of community members involved with the school and attending school events and activities has grown. Many whānau are now attending the open meetings co-ordinated by Ancey, and actively steering the direction of activities such as the recent school fundraising weekend event. 
The original CUPA goal of the community producing its own food for its children has also been met: ... we created solutions for feeding our children that means that they can have an organic lunch at the cost of ten cents per child. That solution entirely belongs to the community. (Julia, CUPA project coordinator)

The projects have opened up opportunities for all kinds of people from the community to work alongside each other, and with children, to share their knowledge and contribute to each other's wellbeing:

It brings us together ... [the knitting project] involves some of our retired people from the wider community who are often not given a space or place in community but actually they're a wealth, they are an absolute powerhouse of knowledge and skill. (Julia, CUPA project coordinator)

As mentioned previously, some paid jobs have also been created to support the community members' projects and micro-enterprise initiatives, with benefits of these flowing both to the school and the wider community. 


\section{8. \\ Sharing the learning with other schools and communities}

The adults we interviewed at Epuni Primary School and CUPA tended to underscore the uniqueness of their collaboration, the community and the relationships and trust between the people involved:

What makes it work is the people. The project is unique and may not be replicable. (Principal)

Other schools and communities have been interested in what is happening at Epuni and want to come and visit. Responding to this interest can be a balancing act between engaging and involving visitors (not just having visitors come and "watch"), while also not overloading or disrupting school and classroom plans and routines.

Students also talked about community people coming into the school to learn alongside them in a reciprocal manner:

I reckon it helps them learn new stuff and us learn new stuff. And it sometimes helps their child keep learning. (Year 4 student)

Maybe they wanted to grow lavender but weren't sure what season to do it; they could come when we are getting taught by Julia. Sometimes when we are learning a particular flower she will know when is the best time to plant it and when roughly is the best time to harvest it. (Year 6 student) 


\section{9. \\ Conclusion}

The collaboration between Epuni Primary School and CUPA seems to be strongly based on relationships and a set of shared values, though there are also clearly ways in which the two organisations differ in the details of their approaches to community involvement, and some of their other priorities for learners and learning. Some of the enabling conditions that seem to have supported the collaboration include:

- the energy, vision and commitment from the leaders of the school and CUPA, built around a relationship of trust and good will

- shared values around the importance of community connection, reciprocity and putting children at the centre

- sensitivity to the community's aspirations, views and ways of wanting to be involved with the school

- the school's relatively small size (in student and staff numbers) but with enough space on the school grounds, and in the school buildings, to support a range of activities.

Working with deliberate care and consideration has thus far allowed the two organisations to each evolve and expand their community connections and nurture goodwill and trust. Since the collaboration has been built on a few essential relationships, the sustainability of the collaboration and what it might look like in the future remains to be seen. The school has established and maintained community connections beyond CUPA, encouraging parents and whānau to participate in determining the direction of school focuses and activities. The school is firmly rooted in its community and has established a culture that supports the school and community to provide reciprocal nurturing, care and learning. For CUPA, the hope is that initiatives like that which has flourished at Epuni, where the community creates and owns its own solutions to challenges like providing nourishing food for all its children, could develop elsewhere:

... up and down New Zealand in various shapes and forms and sizes, and I don't think that it always needs to be as huge as what we have got here, but that there are aspects [that can be replicated], if we keep open sourcing and sharing that it is a way of scaling for us. (Julia, CUPA project coordinator)

For Epuni Primary School, the focus is on maintaining its own community connections and engagement and continuing to nurture students and whānau. The future direction of the school's relationship with CUPA, and the sustainability of the various activities in and around the school that have emerged and grown out of the original garden project, remain to be seen. 


\section{References}

Bolstad, R., \& Gilbert, J., with McDowall, S., Bull, A., Boyd, S., \& Hipkins, R. (2012). Supporting future-oriented learning and teaching-A New Zealand perspective. Wellington: Ministry of Education.

Flyvbjerg, B. (2006). Five misunderstandings about case study research. Qualitative Inquiry, 12, 219-245.

McDowall, S., \& Whatman, J. (2016a). All the school's a stage. Pakuranga Intermediate School. Wellington: NZCER. http://www.nzcer.org.nz/research/publications/all-schools-stage-schools-collaborating-experts-community

McDowall, S., \& Whatman, J. (2016b). Creating a belonging place. Owairaka District School. Wellington: NZCER. http:// www.nzcer.org.nz/research/publications/creating-belonging-place

Yin, R. (2003). Case study research: Design and methods (5th ed.). Thousand Oaks, CA: Sage Publications. 




